\title{
Periodic Drop Thumb, Hypokalemia and Adrenal Adenoma
}

\author{
Chi Chui $^{\mathrm{a}}$ Wei-Hsi Chen ${ }^{\mathrm{b}}$ Hsin-Ling Yin ${ }^{\mathrm{c}}$ \\ a Department of Neurosurgery, Paochien Hospital, Pingtung, ${ }^{b}$ Department of Neurology, Kaohsiung Chang Gung \\ Memorial Hospital and College of Medicine, Chang Gung University, and ' Department of Pathology, Faculty of \\ Forensic Medicine, Kaohsiung Medical University Hospital and College of Medicine, Kaohsiung Medical University, \\ Kaohsiung, Taiwan, ROC
}

\section{Key Words}

Thumb · Hypokalemia $\cdot$ Periodic paralysis · Adrenal adenoma $\cdot$ Weakness

\begin{abstract}
Objective: To report an unusual involvement of focal distal muscles but not proximal muscles in a patient with hypokalemic periodic paralysis (hypoPP). Clinical Presentation and Intervention: A middle-aged woman presented with episodic weakness of the bilateral thumbs lasting for 2 years. Hypokalemia and a left adrenal mass were subsequently found. Her weakness subsided after surgical removal of the adrenal mass, which was pathologically proven to be an adrenal adenoma. Conclusion: The findings for this patient should alert physicians to consider focal distal motor paresis due to hypoPP. A preexisting occult trauma may predispose to paralysis at an atypical location in secondary hypoPP.
\end{abstract}

Copyright $\odot 2013$ S. Karger AG, Basel

\section{Introduction}

Hypokalemic periodic paralysis (hypoPP) is a clinical syndrome of episodic flaccid muscle paresis related to hypokalemia. hypoPP is a hereditary channelopathy in many patients. However, some secondary disorders can also provoke hypoPP [1]. Generally, hypoPP presents as symmetric weakness of the proximal limb muscles. In some cases, the orofacial or respiratory muscle is involved. An isolated distal focal weakness is rarely mentioned in hypoPP. We hereby report a focal distal motor paresis due to hypoPP.

\section{Case Report}

A 48-year-old woman, a musician and piano teacher for more than 20 years, complained of a relapsing and remitting attack of left thumb weakness that had occurred 3 times over the previous 2 years. In each attack, she was completely unable to extend her left thumb and the weakness lasted for 3-7 days. During attacks, she could still move her thumb towards her palm or grasp objects properly. There was no associated pain, sensory change or joint pain of her left hand. A milder right thumb weakness, which spontaneously recovered within $24 \mathrm{~h}$, occurred during the second and third attacks. She denied having a high-calorie or carbohydrate diet, emotional change, or infection before the attack. Stage II hypertension (classified according to Joint National Commission 6 criteria) had been diagnosed 3 years previously and was well controlled by amlodipine besylate. She denied having had recent craniofacial injury, nutrition or herbal supplement, illicit drug usage, or consumption of alcohol. There were no familial diseases, thyroid disorder or neuromuscular disorder known in 3 generations of her family.

She presented $4 \mathrm{~h}$ after the onset of her fourth attack. On presentation, she was oriented and cooperative. Her vital signs were normal. She could not extend or elevate her left thumb (fig. 1a).

\begin{tabular}{ll}
\hline KARGER & $\begin{array}{l}\text { () 2013 S. Karger AG, Basel } \\
1011-7571 / 14 / 0231-0080 \$ 39.50 / 0 \quad \text { Karger }\end{array}$ \\
$\begin{array}{l}\text { E-Mail karger@karger.com } \\
\text { www.karger.com/mpp }\end{array}$ & $\begin{array}{l}\text { This is an Open Access article licensed under the terms of the } \\
\text { Creative Commons Attribution-NonCommercial 3.0 Un- } \\
\text { ported license (CC BY-NC) (www.karger.com/OA-license), } \\
\text { applicable to the online version of the article only. Distribu- } \\
\text { tion permitted for non-commercial purposes only. }\end{array}$
\end{tabular}

Dr. Hsin-Ling Yin

Department of Pathology, Kaohsiung Medical University Hospital

100 Shih-Chuan 1st Road, San-Min District

Kaohsiung City 807, Taiwan (ROC)

E-Mail schoolyin@cc.kmu.edu.tw 
Fig. 1. The patient could not elevate the thumb when fingers were actively extended at the left hand (a). The contrast-enhanced abdominal computerized tomography showed a low-density mass at the left adrenal gland (b), which was later pathologically proven to be an adrenal adenoma.
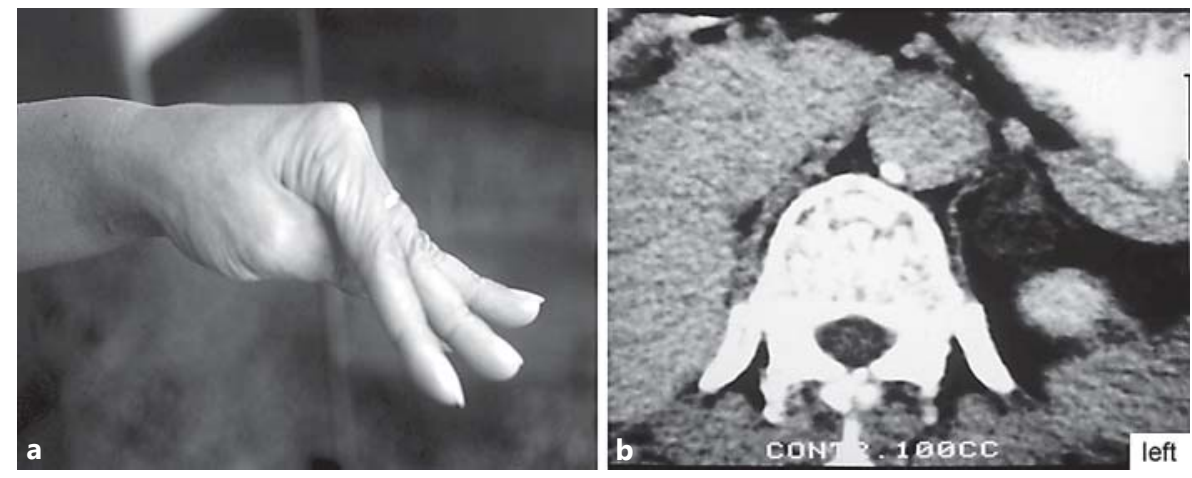

However, she could normally and powerfully move her left thumb towards her palm, flex her left fingers, extend or flex the wrist, elbow and shoulder. No significant weakness of the right thumb was detected. Pinprick pain, fine touch, and cold/warm sensation were normal. Tendon reflexes were symmetric and normoactive. There were no other abnormal neurologic findings. A drop thumb was diagnosed. Nerve conduction studies did not show conduction velocity slowing in the median, ulnar or radial nerves. Needle electromyogram did not show abnormal spontaneous activity in the extensor pollicis brevis and extensor pollicis longus muscles. Laboratory tests, including biochemistry, muscle enzymes, hematology, serology, autoimmune indices, and serum concentration and daily urine excretion of magnesium and calcium, were within reference range, except hypokalemia [1.9 $\mathrm{mEq} / \mathrm{l}$ (reference range: 3.4-5.0)] and mild metabolic alkalosis. Thumb weakness was dramatically reversed by a replacement of potassium to $2.6 \mathrm{mEq} / \mathrm{l}$.

Based on profound hypokalemia, episodic focal muscle paresis, and a rapid reversal of muscle paresis after potassium replacement, hypoPP was considered. Thyroid function and pituitary-adrenal gland axis were normal. The plasma renin activity was $0.3 \mathrm{ng} / \mathrm{ml} / \mathrm{h}$ (reference range: $0.5-3.3$ ) and serum aldosterone level was $84 \mathrm{ng} /$ $\mathrm{dl}$ (reference range: $<31$ ) in the supine position. The aldosterone/ renin ratio was 28 . Conn's syndrome was diagnosed. Abdominal computerized tomography demonstrated a left adrenal mass (fig. 1b). The patient underwent surgical removal of her adrenal mass. Pathologically, the mass was shown to be an adrenal adenoma. After surgery, the patient did not experience any further episodes of thumb weakness, and her serum potassium and aldosterone levels and plasma renin activity were normalized. She discontinued antihypertensive drugs 6 months later as her blood pressure remained normal. During a 12-year follow-up, she remained well without recurrence of weakness, hypertension or hyperaldosteronism.

\section{Discussion}

Our patient exhibited an unusual weakness confined to bilateral thumbs, in contrast to a symmetric proximal muscle weakness in typical primary and secondary forms of hypoPP. Atypical weakness, such as asymmetric or focal motor paresis $[1,2]$ mimicking peripheral neuropathy [3] or hemiparesis [4], has been reported on occasion. These atypical presentations, including the patient reported herein, challenge the physician trying to make an accurate diagnosis. Since profound hypokalemia can cause lethal cardiac dysrhythmia [5] which can be rapidly corrected by potassium replacement, the physician should be aware of possible hypoPP in focal weakness without other definite causes of pure asymmetrical muscle paresis.

Currently, primary hypoPP is a recognized genetic channelopathy with mutations in the CACNA1S or SCN4A gene, but mutations are not found in secondary hypoPP patients. In Conn's syndrome, such as in our patient, the hyperaldosteronism promotes intracellular potassium shifting by increasing the activity of $\mathrm{Na} / \mathrm{K}$-adenosine triphosphatase (ATPase) pump in skeletal muscle [6]. There was no identified triggering factor in our patient for her serial recurrences of focal thumb weakness. The mechanism of paralysis may be complex and the $\mathrm{Na} / \mathrm{K}$-ATPase pump activity can be affected by a variety of conditions. For example, a transient oversecretion of aldosterone or glucocorticoid by adrenal adenoma may rapidly activate the $\mathrm{Na} / \mathrm{K}$-ATPase pump activity.

The consistent and repetitive focal thumb weakness in our patient suggests that some other factor may have played a role in producing this unusual distal asymmetrical muscle weakness. Na/K-ATPase pump activity can be asymmetrically distributed [7] and vary greatly in response to stress or exercise in different skeletal muscles [8]. Trauma is known to enhance the $\mathrm{Na} / \mathrm{K}$-ATPase pump activity. In our patient, frequent exercise of her thumb in her occupation and hyperaldosteronism may have cooperatively increased $\mathrm{Na} / \mathrm{K}$-ATPase pump activity predis- 
posing for periodic paralysis at the left thumb instead of the typically observed symmetrical proximal muscle weakness. The removal of the adrenal adenoma and a normalization of aldosterone hemostasis decreased the hypersensitive $\mathrm{Na} / \mathrm{K}$-ATPase pump activity and therefore, reduced paretic attack in our patient.

Besides mineralocorticoid receptor antagonists, a variety of angiotensin receptor blockers and calcium channel blockers, such as amlodipine besylate, can also lower the aldosterone-mediated arterial hypertension [9]. A favorable antihypertensive effect by amlodipine besylate in a Conn syndrome-associated hypoPP patient [10] as ours may be due to an inhibition of aldosterone secretion [9] and a lower severity of hypertension.

\section{Conclusion}

The findings for this patient should alert physicians to consider focal distal motor paresis due to hypoPP. A preexisting occult trauma may predispose to paralysis at an atypical location in secondary hypoPP.

\section{References}

1 Rao N, John M, Thomas N, et al: Aetiological, clinical and metabolic profile of hypokalaemic periodic paralysis in adults: a single-centre experience. Natl Med J India 2006;19:246249.

$>2$ Hiraga A, Kamitsukasa I, Kojima K, et al: Clinical features and recovery patterns of acquired non-thyrotoxic hypokalemic paralysis. J Neurol Sci 2012;313:42-45.

3 Morishita S, Sakakibara T, Tanaka F, et al: A case of acute bilateral interosseous nerve palsy associated with severe hypopotassemia (in Japanese). Rinsho Shinkeigaku 1993;33: 1070-1074.
4 Lu YT, Lan MY, Liu JS, et al: An unusual presentation of hypokalemic paralysis with evolving pure motor hemiparesis. J Clin Neurosci 2011;18:716-719.

5 Chen WH, Yin HL, Lin HS, et al: Delayed hypokalemic paralysis following a convulsion due to alcohol abstinence. J Clin Neurosci 2006;13:453-456.

6 Phakdeekitcharoen B, Kittikanokrat W, Kijkunasathian $\mathrm{C}$, et al: Aldosterone increases $\mathrm{Na}^{+}-\mathrm{K}^{+}$-ATPase activity in skeletal muscle of patients with Conn's syndrome. Clin Endocrinol (Oxf) 2011;74:152-159.

7 Huang F, Rabson D, Chen W: Distribution of the NA/K pumps' turnover rates as a function of membrane potential, temperature, and ion concentration gradients and effect of fluctuations. J Phys Chem B 2009;113:8096-8102.
8 McMorrow C, Fredsted A, Carberry J, et al: Chronic hypoxia increases rat diaphragm muscle endurance and sodium-potassium ATPase pump content. Eur Respir J 2011;37: 1474-1481.

9 Mulatero P, Rabbia F, Milan A, et al: Drug effects on aldosterone/plasma renin activity ratio in primary aldosteronism. Hypertension 2002;40:897-902.

10 Vhora RA, Gadani MK, Shah HS, et al: A rare case of hypokalemic paralysis - Conn's syndrome. Indian J Clin Pract 2012;22:33-35. 